\title{
$\alpha-\mathrm{Fe}_{2} \mathrm{O}_{3}$ 基纳米材料催化和气敏性质的研究*
}

\author{
孙 䑣** 沈瑜生 刘 勇 \\ (中国科学技术大学材料系, 合肥 230026)
}

\section{关键词 $\alpha-\mathrm{Fe}_{2} \mathrm{O}_{3}$ 材料电导 催化性能 气敏特性}

$\alpha-\mathrm{Fe}_{2} \mathrm{O}_{3}$ 作为良好的气繁基体材料得到了广泛应用 ${ }^{[1]}$, 而钻钛石型复合氧化物 $\mathrm{ABO}_{3}(\mathrm{~B}$ 为 $\mathrm{Mn}$, $\mathrm{Fe}, \mathrm{Co}$ 元素) 被认为是优良的催化剂 ${ }^{[2,3]}$. 遗憾的是, 至今尚未有人对 $\alpha-\mathrm{Fe}_{2} \mathrm{O}_{3}$ 系纳米材料的 气敏性能与其催化能力之间联系作深人的研究. 我们采用共沉淀的方法合成了一系列碱土金 属掺杂的 $\alpha-\mathrm{Fe}_{2} \mathrm{O}_{3}$ 纳米材料, 初步探讨了晶粒尺寸、材料电导、催化性能与气敏特性的关系.

\section{1 实验部分}

\section{1 纳米材料制备}

按最终氧化物重量比配成硝酸盐溶液, 用碳酸铵沉淀, 抽滤, 洗涤, 干燥, 经 $600{ }^{\circ} \mathrm{C}, 3 \mathrm{~h}$ 热 处理得粉料, 由 XRD 确定其物相及粒径.

\section{2 催化性能}

在自制的催化性能测试装置上完成, 当还原性气体流经粉料表面时, 发生氧化还原反应, 测量其反应热, 表示为温升 $\Delta T$.

\section{2 结果与讨论}

\section{1 掺杂对 $\alpha-\mathrm{Fe}_{2} \mathrm{O}_{3}$ 晶粒尺寸的影响}

各掺杂体系的晶粒尺寸见表 1. 可见 $\mathrm{BaO}$ 对 $\alpha-\mathrm{Fe}_{2} \mathrm{O}_{3}$ 晶粒生长的抑制作用最大, 这与 $\mathrm{BaO}$ 在 $\alpha-\mathrm{Fe}_{2} \mathrm{O}_{3}$ 表面的分散程度和在 $\alpha-\mathrm{Fe}_{2} \mathrm{O}_{3}$ 中的固溶情况有关, XRD 分析结果表明, 各掺杂体系 经 $600{ }^{\circ} \mathrm{C}$ 锻烧无新相生成, 但 $\alpha-\mathrm{Fe}_{2} \mathrm{O}_{3}$ 晶格有不同程度的畸变.

表 1 碱土金属氧化物掺杂 $\alpha-\mathrm{Fe}_{2} \mathrm{O}_{3}$ 样品的晶粒尺寸

\begin{tabular}{cccccc}
\hline 样 品 & $\alpha-\mathrm{Fe}_{2} \mathrm{O}_{3}$ & $\mathrm{MgO}-\alpha-\mathrm{Fe}_{2} \mathrm{O}_{3}$ & $\mathrm{CaO}-\alpha-\mathrm{Fe}_{2} \mathrm{O}_{3}$ & $\mathrm{SrO}-\alpha-\mathrm{Fe}_{2} \mathrm{O}_{3}$ & $\mathrm{BaO}-\alpha-\mathrm{Fe}_{2} \mathrm{O}_{3}$ \\
\hline 粒径 $/ \mathrm{nm}$ & 26.5 & 24.3 & 21.2 & 25.1 & 18.4 \\
\hline
\end{tabular}

\section{2 材料电导、催化反应热与气敏性能之间关系}

图 1 是材料电导 - 温度曲线. 5 种体系均表现出类似 $\mathrm{SnO}_{2}$ 的有氧化学吸附电导峰的特

1994-04-19 收稿, 1994-12-28 收修改稿

*国家自然科学基金资助项目

**现在工作单位: 中国国际人才交流协会美大一部, 北京 100873 
征, 其中 $\mathrm{SrO}-\alpha-\mathrm{Fe}_{2} \mathrm{O}_{3}$ 体系表面电导最大, $\mathrm{BaO}-\alpha-\mathrm{Fe}_{2} \mathrm{O}_{3}$ 体系次之. 而材料的表面电导在低 温段主要由材料的表面吸附氧 ( $\alpha$ 氧) 贡献, 高温段主要由材料的本征电导决定. 这说明温度 低于 $400^{\circ} \mathrm{C}$ 时, $\mathrm{SrO}, \mathrm{BaO}$ 掺杂材料表面存在着较多的 $\alpha$ 氧; $\mathrm{SrO}$ 体系的表面电导高于 $\mathrm{BaO}$ 体 系, 主要原因在于 $\mathrm{BaO}$ 掺杂体系的 $\alpha-\mathrm{Fe}_{2} \mathrm{O}_{3}$ 晶粒尺寸最小, 同时 $\mathrm{Ba}$ 的离子半径大于 $\mathrm{Sr}$, 因而 $\mathrm{BaO}$ 大多分散在晶界和晶粒表面, 材料的电阻中晶界部分占有较 $\mathrm{SrO}$ 体系大的比例 ${ }^{[4]}$.

表 2 各掺杂体系的气敏灵敏度数据 (样气, 乙醇; 浓度, $\left.1000 \times 10^{-6}\right)^{\mathrm{a})}$

\begin{tabular}{cccccr}
\hline 元 件 & $\alpha-\mathrm{Fe}_{2} \mathrm{O}_{3}$ & $\mathrm{MgO}-\alpha-\mathrm{Fe}_{2} \mathrm{O}_{3}$ & $\mathrm{CaO}-\alpha-\mathrm{Fe}_{2} \mathrm{O}_{3}$ & $\mathrm{SrO}-\alpha-\mathrm{Fe}_{2} \mathrm{O}_{3}$ & $\mathrm{BaO}_{-}-\alpha-\mathrm{Fe}_{2} \mathrm{O}_{3}$ \\
\hline $350 \mathrm{C}$ & 2.8 & 2.4 & 1.8 & 3.5 & 6.1 \\
$400^{\circ} \mathrm{C}$ & 3.0 & 1.6 & 1.4 & 4.3 & 7.5 \\
$450 \mathrm{C}$ & 1.5 & 1.1 & 1.0 & 1.5 & 2.3 \\
\hline
\end{tabular}

a) $S$ 即为气敏灵敏度, 表示为 $R_{\text {然 }} / R_{s} ; R_{\text {柽 }}, R_{s}$ 分别为空气、样品气氛中元件的表面电阻

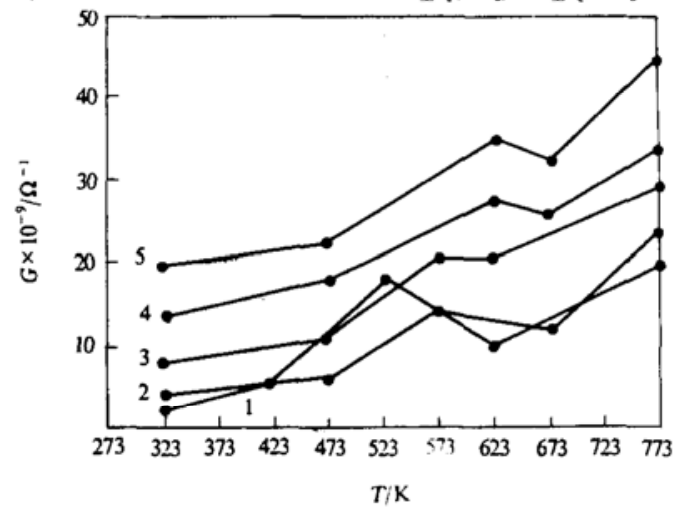

图 1 各掺杂体系电导 - 温度变化图 1 为纯 $\alpha-\mathrm{Fe}_{2} \mathrm{O}_{3}, 2$ 为 $\mathrm{MgO}-\alpha-\mathrm{Fe}_{2} \mathrm{O}_{3}, 3$ 为 $\mathrm{CaO}-\alpha-\mathrm{Fe}_{2} \mathrm{O}_{3}$, 4 为 $\mathrm{SrO}-\alpha-\mathrm{Fe}_{2} \mathrm{O}_{3}, 5$ 为 $\mathrm{BaO}-\alpha-\mathrm{Fe}_{2} \mathrm{O}_{3}$

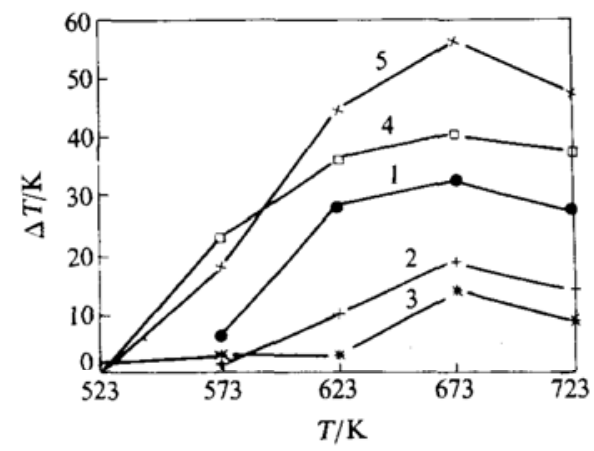

图 2 各掺杂体系气敏灵敏度与工作温度关系 $\left(\mathrm{C}_{2} \mathrm{H}_{2}\right.$ 的体积分数为 $4 \%+$ 空气 )

1 为纯 $\alpha-\mathrm{Fe}_{2} \mathrm{O}_{3}, 2$ 为 $\mathrm{MgO}-\alpha-\mathrm{Fe}_{2} \mathrm{O}_{3}, 3$ 为 $\mathrm{CaO}-\alpha-\mathrm{Fe}_{2} \mathrm{O}_{3}$, 4 为 $\mathrm{SrO}-\alpha-\mathrm{Fe}_{2} \mathrm{O}_{3}, 5$ 为 $\mathrm{BaO}-\alpha-\mathrm{Fe}_{2} \mathrm{O}_{3}$

图 2 反映了各掺杂材料的催化能力, 数据表明 $400{ }^{\circ} \mathrm{C}$ 时各体系的催化性能最佳, 尽管此 时材料的表面电导并非最大, 但温度升高有利于被吸附物质化学键的解离, 有利于 $\alpha-\mathrm{Fe}_{2} \mathrm{O}_{3}$ 生 成氧空位, 对催化氧化还原反应有利. 值得注意的是 $\mathrm{BaO}$ 体系的催化能力居然高于 $\mathrm{SrO}$ 体 系, 对照表 2 的气敏特性测试数据, 我们认为: 对于表面电阻控制型的气敏材料, 其表面拥有 大量的 $\alpha$ 氧, 确实对材料的催化性能有很大影响, $\mathrm{SrO}$ 掺杂体系的催化能力远高于纯 $\alpha-\mathrm{Fe}_{2} \mathrm{O}_{3}$ 体系和 $\mathrm{MgO}, \mathrm{CaO}$ 掺杂体系就很好地说明了这一点, 但这并不是决定性因素, 衡量一个催化体 系的催化活性必须根据该体系自身的再氧化还原速度和活化气相氧分子能力来判断 ${ }^{[5}$. 就 $\alpha-\mathrm{Fe}_{2} \mathrm{O}_{3}$ 体系而言, 影响其催化性能的应是活性中心 $\mathrm{Fe}^{2+(3+)}$ 的再氧化还原能力, 以及气相 氧、表面吸附氧和晶格氧之间的快速平衡能力. 催化氧化反应的第一步是气相氧的活化. 我 们所制备的 $\alpha-\mathrm{Fe}_{2} \mathrm{O}_{3}$ 为纳米粉末, 粒子尺寸小, 尤其是 $\mathrm{BaO}$ 掺杂体系, 晶粒直径更小, 它们有 着相当大的表面吸附能力; 同时晶粒直径减小, 导致 $\alpha-\mathrm{Fe}_{2} \mathrm{O}_{3}$ 偏向于 $\alpha-\mathrm{Fe}_{2} \mathrm{O}_{(3-x)}$. 当 $\alpha-\mathrm{Fe}_{2} \mathrm{O}_{3}$ 工作温度升高, 固体表面氧分压升高, $\alpha-\mathrm{Fe}_{2} \mathrm{O}_{3}$ 产生超过平衡态的氧空位, 这多余部分的氧空 位处于一种介稳态, 其束缚的电子 (氧离去时留下的)往往容易变成准自由电子, 因而当气相氧分 子吸附在催化剂表面, 与氧空位结合时, 得到电子被活化为 $\mathrm{O}^{x-}(0<X<2)$ 而具有催化活性. 
第二步是被吸附的还原性气体分子与活化氧反应.

$\mathrm{BaO}$ 掺杂体系之所以具有最好的催化活性, 是因为少量的 $\mathrm{BaO}$ 掺杂使 材料表面的 Fermi

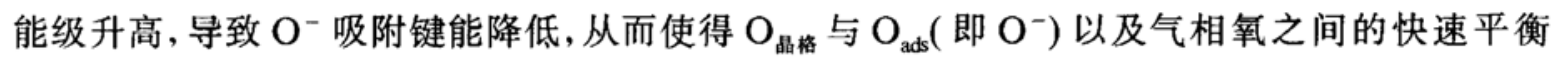
易于达到, 提高了 $\mathrm{O}^{-}$的氧化性, 而这一步常常是表面化学反应的控制步骤[6, 万. 因此, $\mathrm{BaO}-\alpha-$ $\mathrm{Fe}_{2} \mathrm{O}_{3}$ 体系具有较 $\mathrm{SrO}-\alpha-\mathrm{Fe}_{2} \mathrm{O}_{3}$ 好的催化能力.

另外, 该掺杂体系晶粒尺寸较小, 具有较 $\mathrm{SrO}-\alpha-\mathrm{Fe}_{2} \mathrm{O}_{3}$ 大的比表面, 有利于气相氧分子的 吸附和被吸附物质离解成活泼的反应基, 这活泼的反应基与 $\alpha-\mathrm{Fe}_{2} \mathrm{O}_{3}$ 表面的活化氧反应生成 氧化产物并将电子传递给 $\alpha-\mathrm{Fe}_{2} \mathrm{O}_{3}$ 体相, 因而使材料电导显著增加. 在这种催化效应的协同 下, 加上 $\mathrm{BaO}$ 掺杂体系 $\alpha-\mathrm{Fe}_{2} \mathrm{O}_{3}$ 晶粒尺寸最小, 导致空间电荷层的厚度与粒子半径之比相对 高于其它 3 个掺杂体系, 因而显著地提高了 $\mathrm{BaO}-\alpha-\mathrm{Fe}_{2} \mathrm{O}_{3}$ 体系的气敏灵敏度; 同时, $\mathrm{BaO}$ 体系 具有最好的气敏性能 $\left(400{ }^{\circ} \mathrm{C}\right)$, 部分是由此温度下催化反应大量放热, 导致元件表面瞬间温度 升高, 材料表面电导增大产生的, 这是温度变化对元件气敏灵敏度的贡献.

随着元件测试温度进一步提搞, 材料电导主要由本征电导决定, 因而由 $\alpha$ 氧与还原性气体 的反应所产生的电导变化相对而言就减弱很多, 材料的气敏性能普遍下降.

\section{参 考文献}

1 曾桓兴, 王 弘, 沈瑜生. 氧化铁气体传感器研究 II. $\alpha-\mathrm{Fe}_{2} \mathrm{O}_{3}$ 气敏特性. 半导体学报, 1988, 9(6): 648 653

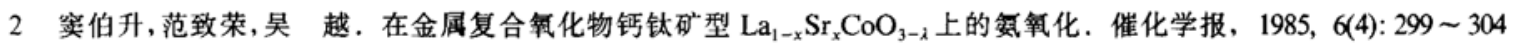

3 于 涛, 吴 越, 吕光烈等. 钻钢石型复合氧化物 $\mathrm{La}_{1-x} \mathrm{Sr}_{x} \mathrm{FeO}_{3-\lambda}$ 催化性能研究 I. 固体结构以及缺陷性质与催化性能的 关系.中国科学, B 辑, 1988, (4): $351 \sim 358$

4 孙 捯, 沈瑜生, 刘 勇. 添加物对 $\mathrm{Fe}_{2} \mathrm{O}_{3}$ 超微粒的稳定作用. 无机材料学报, 1994, 9(1): 107 110

5 王承宪, 突伯升, 范淑荣等. 䥻钛石型催化剂 $\mathrm{Ca}_{x} \mathrm{La}_{1-x} \mathrm{MnO}_{3+i}$ 中的缺陷及其在氨氧化中的作用. 中国科学, $\mathrm{B}$ 辖, 1984, (3): $209 \sim 216$

6 Carberry T J, Kuczynski G C, Martinez E. On the influence of $\gamma$-irradiation upon catalytic selectivity I. oxidation of ethylene over supported silver. J Catal, 1972, 26: $247 \sim 253$

7 Nakamura Teiji, Misono Makoto, Yoneda Yukio. Reduction-oxidation and catalytic properties of $\mathrm{La}_{1-x} \mathrm{Sr}_{x} \mathrm{CoO}_{3}$. J Catal, 1983, 83: $151 \sim 159$ 